\title{
آثر القران الكريم فى اللغة العربية
}

\section{نور هدايات}

مدرس فى قسم اللغة العربية و تربيتها فى جامعة بانكولو الأسلامية الحكومية البريد الإلكتروني : dayat38@yahoo.com

\section{الملخص}

مما لا شك فيه أن أول ما يجب على من بدخل في الإسلام هو تعلم

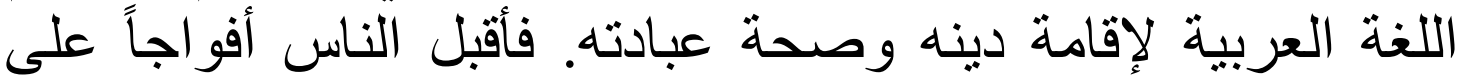

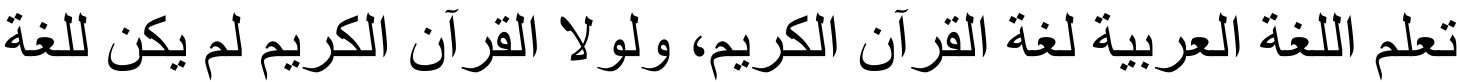

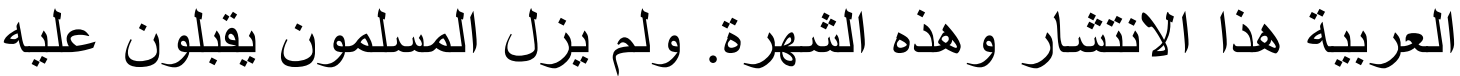

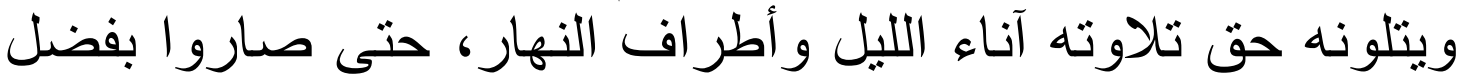
القر آن خير أمة أخرجت جن للناس، بنطقون لغة و احدة عربهم و عجمهم، وكان بذلك جامعاً للعرب و المسلمبن على لغة قريش وما يقاربها، وليس بينهم هذا التفاوت والاختلاف في اللهجات كما كان فبل نزول القرآن، وبذللك دخلوا في مرحلة تاريخية فريدة هي توحد لغتهم

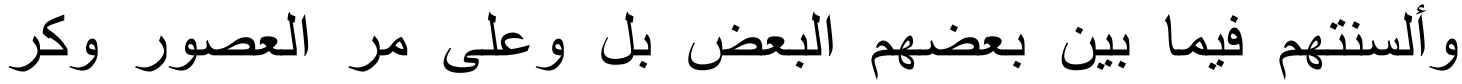
الدهور.

الكلمات الدالة: اثر القران; اللغة العربية; لغة قريش

وكذللك ليس لايهم حضارة أو مقدمة صناعة، كل ذللك جعل اللغة تقبع في ان اللغة هي صورة صادقة جزيرتها فلا تبرح إلا لتعود إليها. لحياة الناطقين بها، والعرب قبل وقد ظلوا كذللك، حتى جاء القرآن نزول القرآن الكريم لم يكن لهم شأن الكريم، يحمل أسمى ما تعرف ويذكر أو موقع بين الأمم حتى تقبل البشرية من مبادى وتعاليم، فدعا الأمم على تعلم لغتهم و التعاون معهم العرب إلى دعوة الآخرين إلى فليست لغتهم لغة علم ومعرفة، 
العربية تأثثر ا بالغا يمكن إجماله فى التي المحاور التالية:

ا ـ حفظ اللغة العربية :

فالمتأمل للتاريح يرى بوضوح لغات كثيرة قد اندثرت بموت أهلها , لأريا

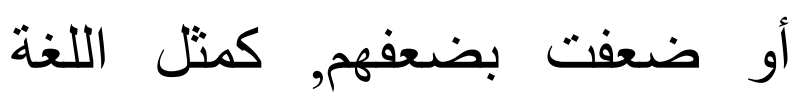
الفينيقية (لغة آهل لبنان قديما ) واللغة المصرية القديمة و اللغة لآشورية.

إن ارتباط اللغة العربية

بالقرآن الكريم جعلها محفوظة بحفظه باقية بيقائه حيث قال تعالى: $\leftarrow \Pi \backsim \bullet \bullet$

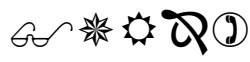

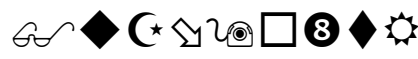

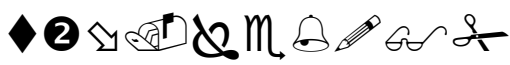

(1)

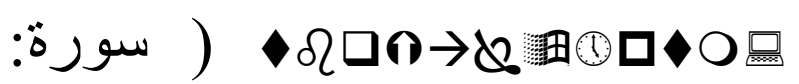

الحجر: 9)

و الذي بدقق النظر فى العربية المعاصرة يجد الكثير من الفاظها

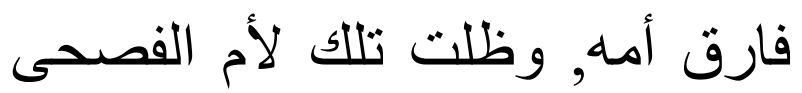
حية مقصورة على الاسخدام الدينى
دينهم، ومما لا شك فيه أن أول ما يجب على من يدخل في الإسلام هو

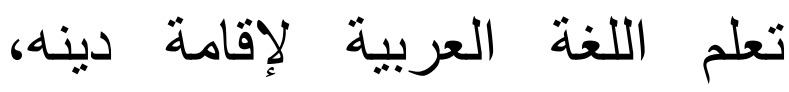
وصحة عبادته، فأقبل الناس أفواجاً على تعلم اللغة العربية لغة القرآن

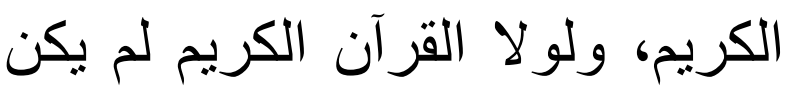
للغة العربية هذا الانتشار ورهذه الثهرة. يقول أ. د. نور الدين عتر: "وقد اتسع انتشار اللغة العربية جداً حتى تغلغلت في الهند و والصين

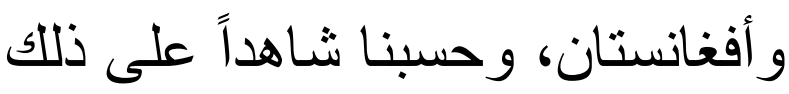

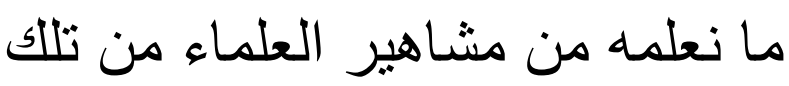

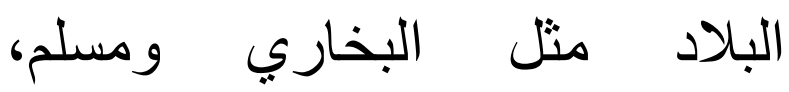
والنسائي، و وابن ماجه القزويني، و غير هم و غير هم" 1

القران الكريم و اثره فى اللغة العربية نزل القران الكريم بلسان عربي مبين , فكان للغة العربية مزية لا تأتى لغيرها من اللغات, فئرن وكما أثر القرآن الكريم فيى لاتير الأمة العربية, فى آخلاقها و عقيدتها وشتى انتى فرئ نواحى حياتها, فقد أثر أيضا فى اللغة فيذاتها

القرآن الكريم و الدر اسات الأدبية د. عتر ، (ط. جامعة دمثق:

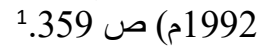


بها، وثابر عليها، وصرف همته إليها، ومن هداه الله للإسلام وشرح وحاير

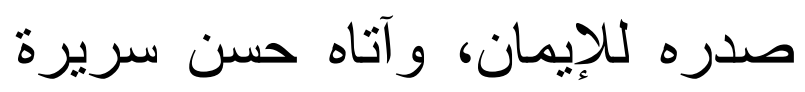

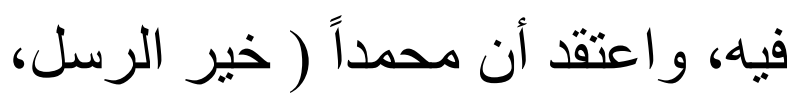

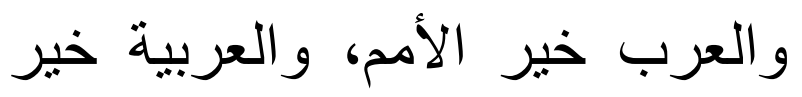

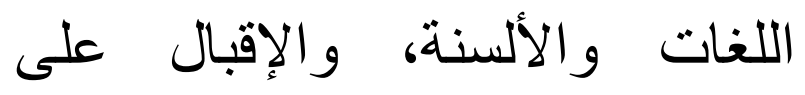
تفهمها من الديانة، إذ هي أداة العلم، ولاتهات

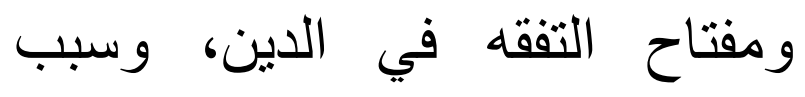

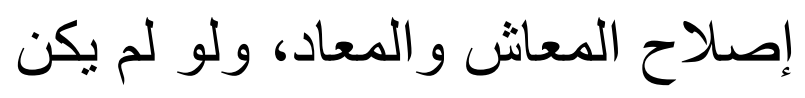
في الإحاطة بخصائصها، و الوقوف ولاحت على مجاريها ومصارفها، و التبحر في جلانٔلها ودقائقها إلا قوة اليقين في معرفة إعجاز القرآن، وزيادة البصيرة في إثبات النبوة التي هي إني

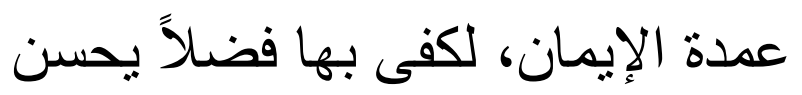

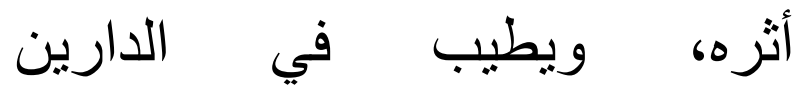
ثمره"4. فبحفظ الله تعالى كتابه بحفظ

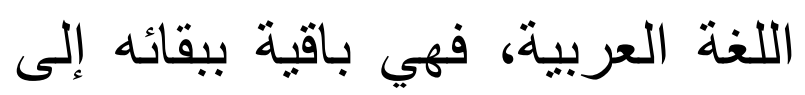

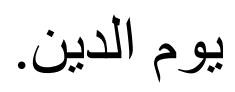

2. تقوية اللغة والرقي بها نحو

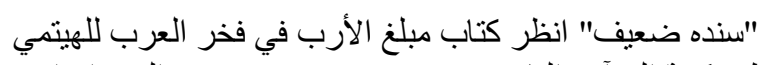

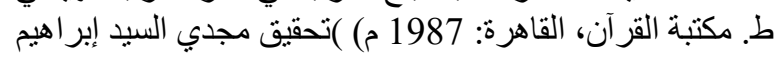

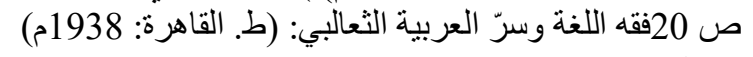

بالقرآن الكريم2 و السنة النبوية

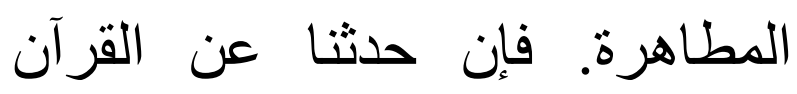
الكريم وأثره في اللغة العرنة العربية،

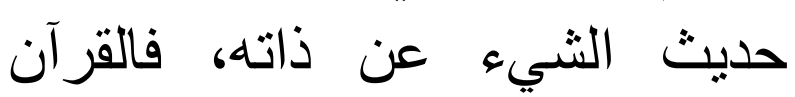

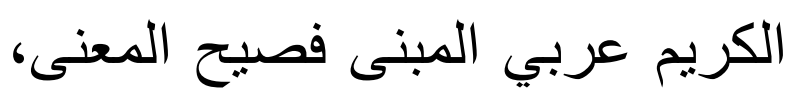
وقد اختار الله تعالى لكتابه أفصح اللغات.

ومن الراجح أن اللغة العربية

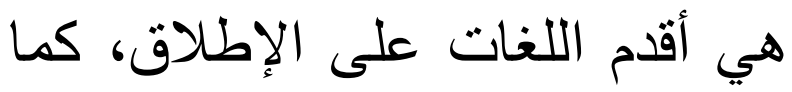
بينت الدراسات الحديثة وأنها اللغة التهات

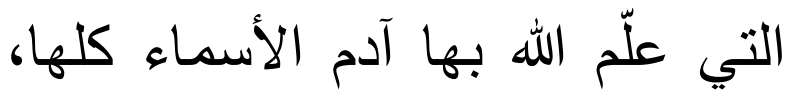

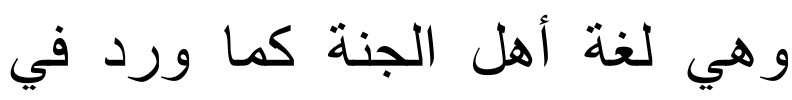
الحديث: "أَحِبوا العرب لثلاث :لأني الني عربي، والقرآن عربي، وكلام أهل الجنة عربي" 3 و ومن هذا المنطلق وعلى نجد الثعالبي يعبر عن هذه اللغة أبلغ تعبير فيقول في مقدمة كتابه الثهير فقه اللغة وسرّ العربية: "من أحب فئية الله تعالى، أحب رسوله محمداً)

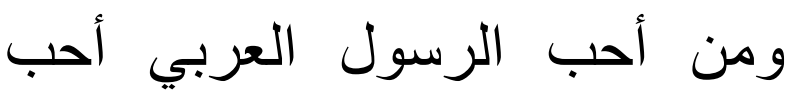

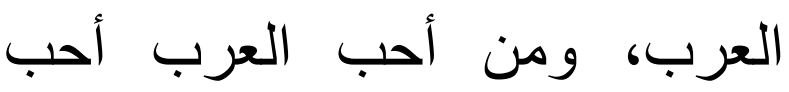
العربية، ومن أحب العربية عني احبي العربي

راجع : د.محمد محمد داود, الدلالة و الكلام , فصل : ألفاظ الكلام و الإستخدام الدينى 2

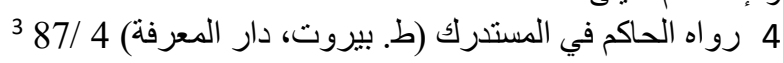


بها في ماء الجمال أملأ من السحاب،

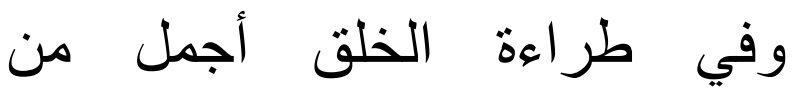
الثباب، ثم هو بما تناول بها من المعاني الدقيقة التي أبرزها في في في جلال الإعجاز، وصور ها بالحقيقة

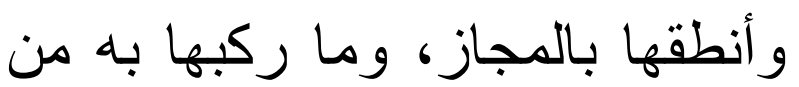

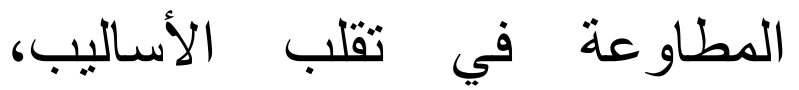
وتحويل التركيب إلى التراكيب، قد

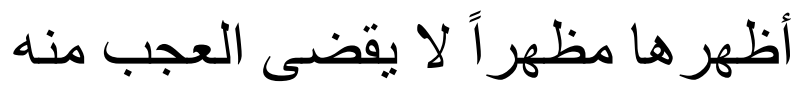

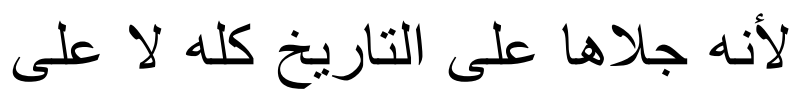
جيل العرب بخاصته، ولهذا بهتوا

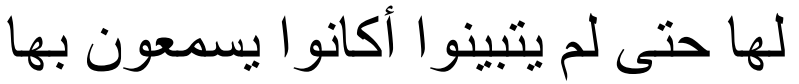
صوت الحاضر أم صوت المستقبل

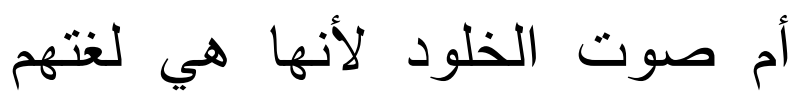
التي يعرفونها ولكن في جزالة لم لمان يمضغ لها شيح و لا قيصوم" هذا ما عبر بـه إمام العربية

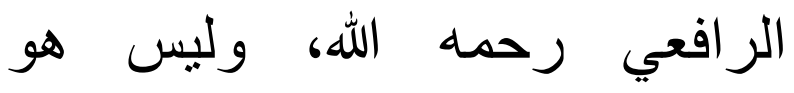
فحسب، بل اعترف أعداء العربية من المستشرقين وغيرهم بقوة اللغة العربية وحيويتها وسر عة انتشار ها، فيقول "أرنست رينان": "من أغرب وسن انغارها
الكمال منح القرآن الكريم اللغة العربية قوة

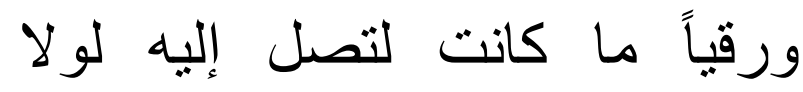

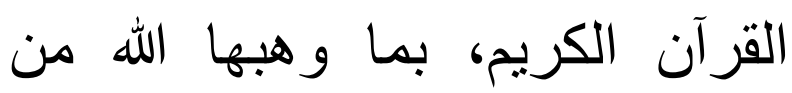

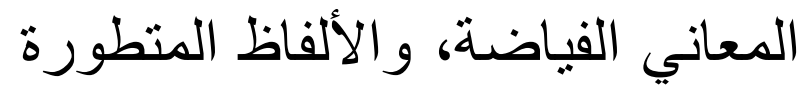

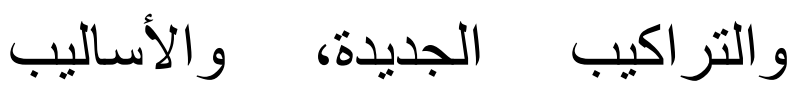

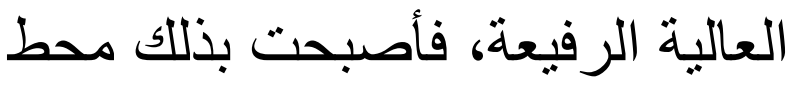
جميع الأنظار، و الاقتباس منها مناط فاهيخ العز و الفخار، و غدت اللغار، والاتة العربية

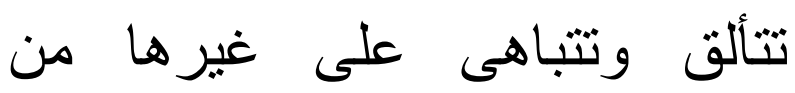
اللغات بما حازت عليه من محاسن

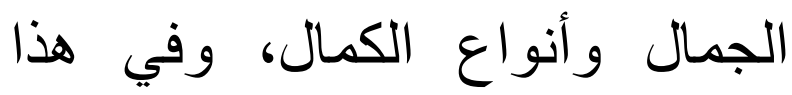
يقول العلآمة الرآن افعي رحمه الله:

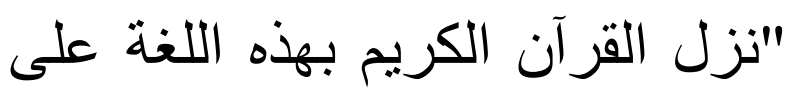
نمط يعجز قليله وكثيره معاً، فكان النئ أثباه شيء بالنور في جملة نسقه إذ

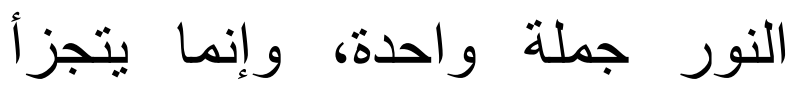

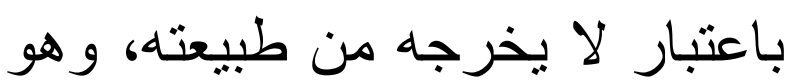

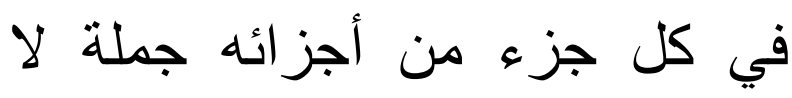
يعارض بشيء إلا إذا خلقت سماء

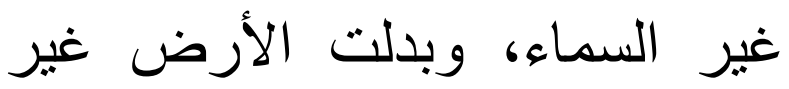
الأرض، و إنما كان ذلك، لأنه صفى وبلى الأرضي

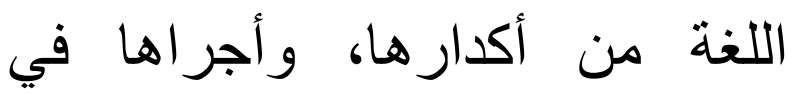
ظاهره على بواطن أسرارها، فجاء 
ويقول جورج سارنوت:

"ولغة القرآن على اعتبار أنها لغة العرب كانت بهذا التجديد كاملة، وقد اعتان و هبها الرسول مرونة جعلتها قادرة الرابة على أن تدون الوحي الإلهي أحسن تدوين بجميع دقائق معانيه ولغاتها الآهي التين وأن يعبر عنه بعبارات علئها طبات طلاوة

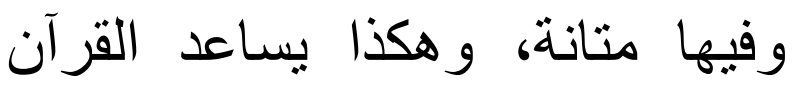
على رفع اللغة العربية إلى مقام

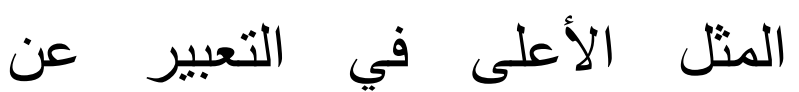
المقاصد.7"

ويقول بروكلمان: "بفضل القرآن بلغت العربية من الاتساع بروكاع مدى لا تكاد تعرفه أي لغة أخرى الاتي الغاع من لغات الدنيا، والمسلمون جميعاً

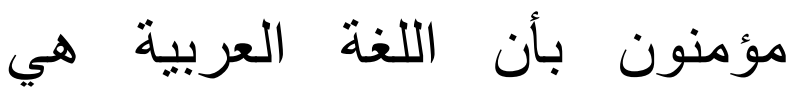
وحدها اللسان الذي أحل لهم أن

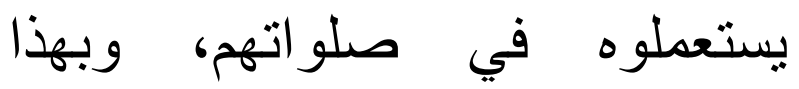
اكتسبت اللغة العربية منذ زمان التهان طويل رفيعة فاقت جميع لغات الدنيا

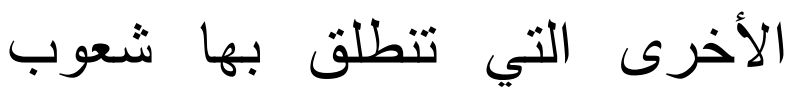
إسلامية"8. ومما لا شك فيه أن فيه

لغة القرآن الكريم د. عبد الجليل عبد الرحيم، (ط. مكتبة الرسالة

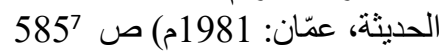
تاريخ الأدب العربي كارل بروكلمان، 1 / $23^{8}$
ما وقع في تاريخ البشر، وصعب

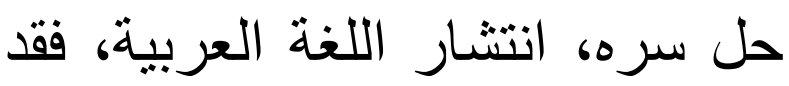
كانت هذه اللغة غير معروفة بادئ بدء، فبدأت فجأة في غاية الكمال، سلسة أي سلاسة، غنية أي غنى، فئ، كاملة بحيث لم يدخل عليها إلى يومنا هذا أي تعديل مهم، فليس لها طفولة لإنة

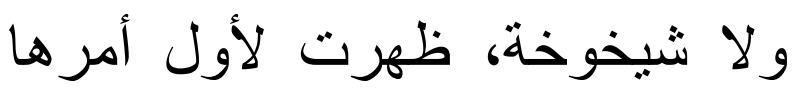

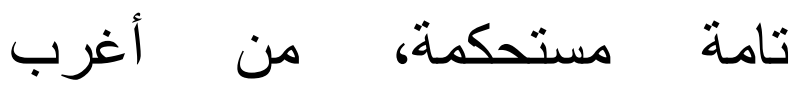
المدهشات أن تنبت تلك اللغة القومية

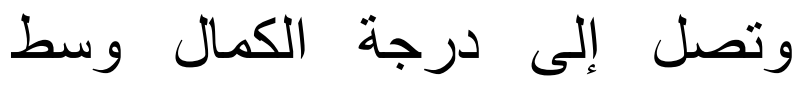
الصحارى عند أمّة من الرحل، تلكي الكال اللغة التي فاقت أخواتها بكثرة التهات مفرداتها ودقة معانيها، وحسن نظام مبانيها، وكانت هذه اللغة مجهولة ودنة عند الأمم، ومن يوم علمت ظهان الفهرت

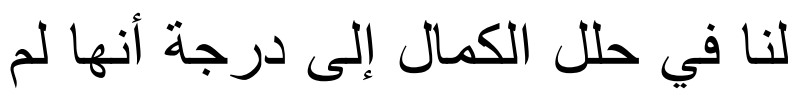

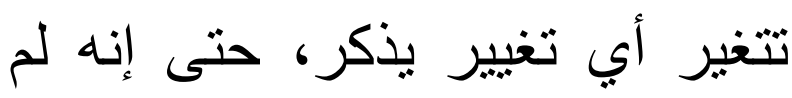

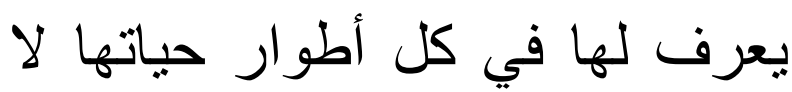
طفولة ولا شيخوخة، ولا نا نكاد نعلم

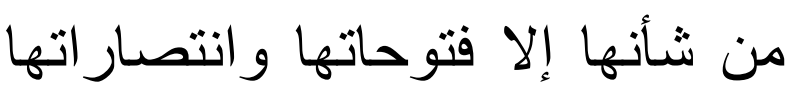
التي لا تبارى..."

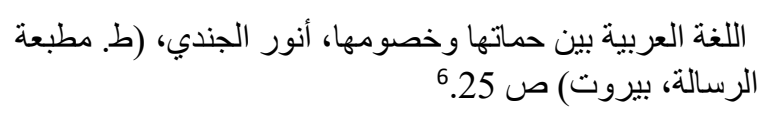


معتدة بلهجتها حتى إن القرآن الكريم نزل على سبعة أحرف من أجل إنل التخفيف على العرب في قراءته وتلاوته، ولا شُكّ أن لغات العرب

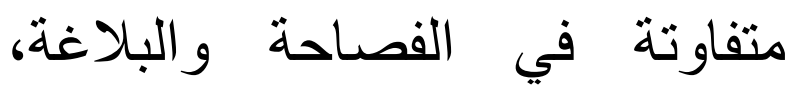
ولذلك نجد عثمان رضي الله عنه قد ولد راعى هذا الجانب في جمعه للقرآن، وقال للجنة الرباعية: "إذا اختلفتم أنتم فاكتبوه بلسان قريش فإنه إنما نزل بلغتهم" وما ذلك إلا لأن لغة لغة فئه

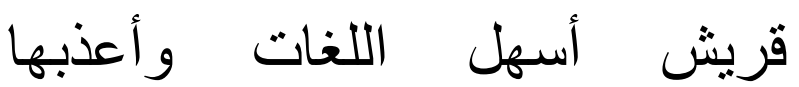
وأوضحها و أبينها، وكانت تحتوي

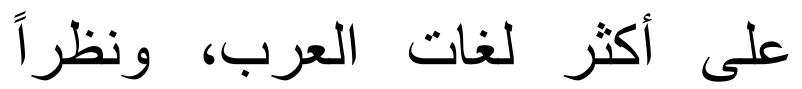
لكونهم مركز البلاد و إليهم يأوي العباد من أجل الحج أو التجارة، فقد

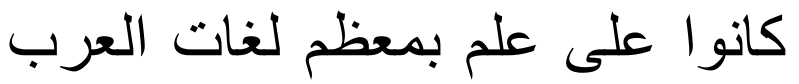

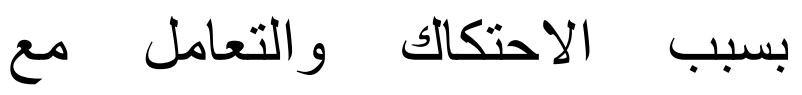
الآخرين، ولكن لغتهم أسهل اللغات

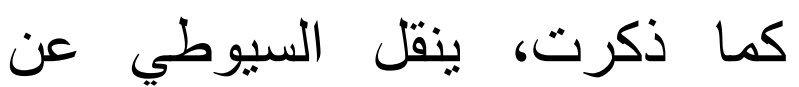

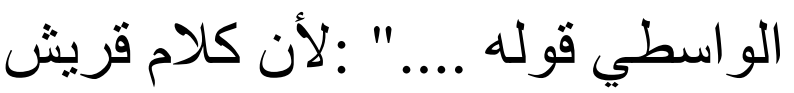
سهل واضح، وكلام العرب وحشي لان فلهي

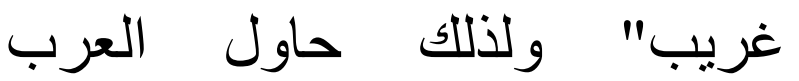
الاقتر اب منها، وودوا لو أن ألسنتهح انطبعت عليها حين رأوا هذا القرآن آن النقان
اعتر اف أمثال هؤلاء، لا يقوي من

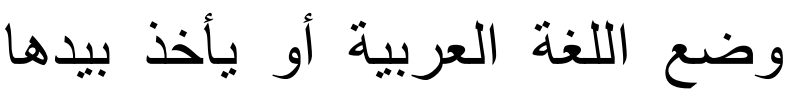

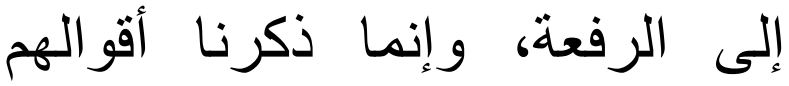
لنبين أن الفضل ما شهدت بـاء

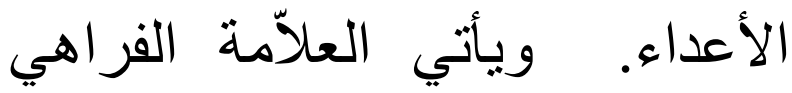

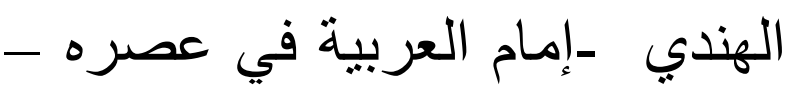
ليقول عن اللغة العربية: "أعلم أن كلام العرب كله نمط أعلى من كلام الأمم الذي تعودت به، لأنهم مولعون اعلى من كرن

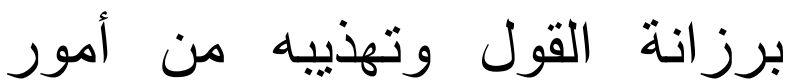
سخيفة، فهم يجردون كلامهم من كل فئل

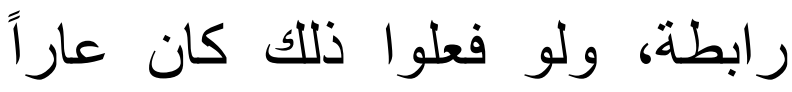

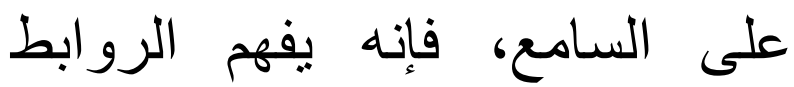
بذكائه، فلذلك كثر فيهم الحذف فئ..." 3. توحيد لهجات اللغة العربية وتخليصها من اللهجات القبلية الكثيرة من المعلوم أن لجهات اللغة

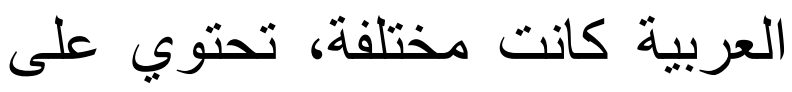

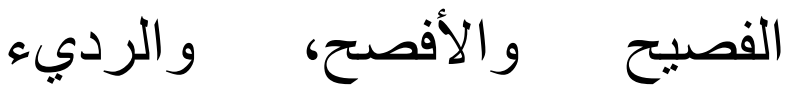
و المستكره، وكانت القبائل العربية والردية

دلائل النظام (ط2، الدائرة الحميدية الهندية: 1991م) ص 97 
ومن المعروف أن العرب قبل

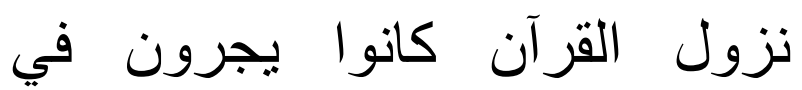
كلامهم و أشعار هم وخطبهم على لتى

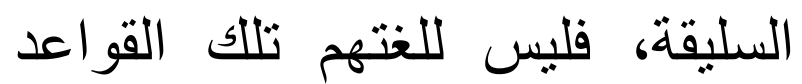
المعروفة الآن، وذللك لعدم الحاجة إليها، ولا أدل على ذلك من أن أن التاريخ يحدثنا عن كثير من العلماء الذين صرحوا أن لغتهم استقامت لئّا

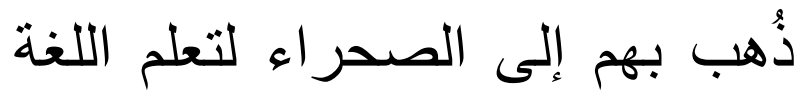

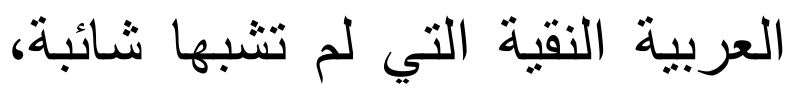

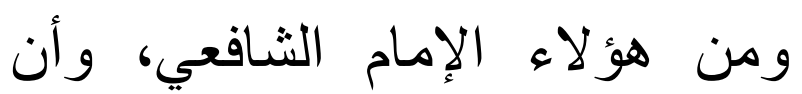
الوليد بن عبد الملك كان كثير اللحن،

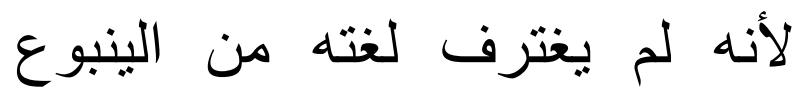
العربي الصحر اوي الصافي.

ولما اتسعت الفتوح، وانتشر الإسلام، ودخل الناس في دين الله أفو اجاً، احتلك العجم بالعرب فأفسدوا

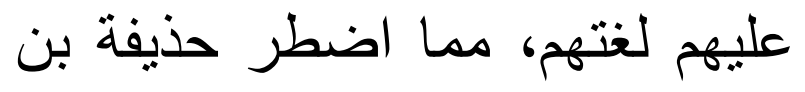
اليمان الذي كان بغازي أهل الثام في فتح إرمينية وأذربيجان مع أهل الهان الهان العراق، أن ليرجع إلى المدينة

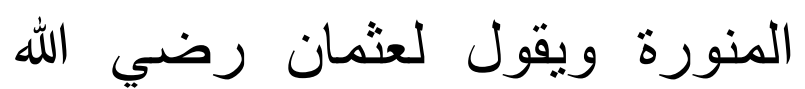
عنه: "يا أمير المؤمنين أدرك هذئ رئهي الأمة قبل أن تختلف في كتابها
يزيدها حسناً، ويفيض عليها عذوبة،

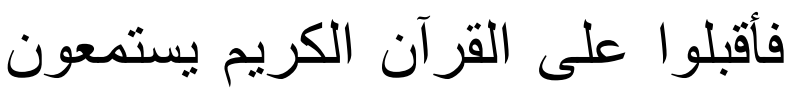
إليه، فقالوا على الرغم من أنفهم: "إن له لحلاوة وإن عليه لطلاوة، إنها.

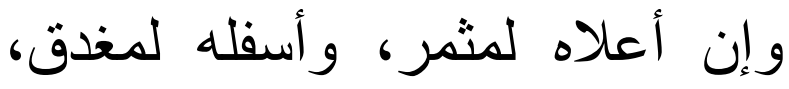

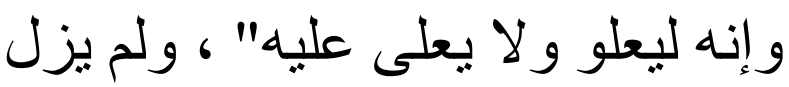

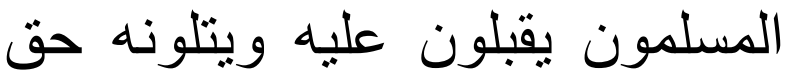
تلاوته آناء الليل و أطراف الف النهار، ونله

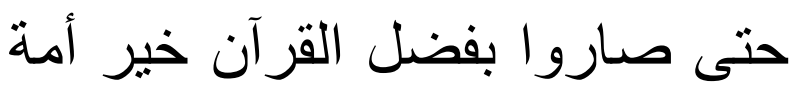
أخرجت للناس، بنطقون لغة واحدة عربهر و عجمهم، وكان بذللك جامعاً

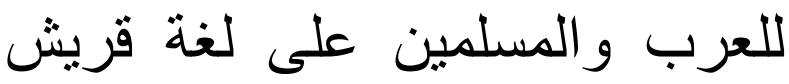
وما يقاربها، وليس بينهم هذا التفاوت لئه والاختلاف في اللهجات كما كان قبل

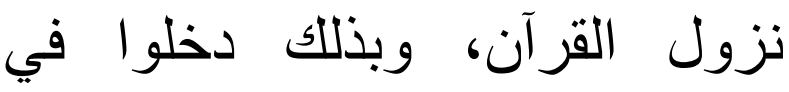
مرحلة تاريخية فريدة هي توحد

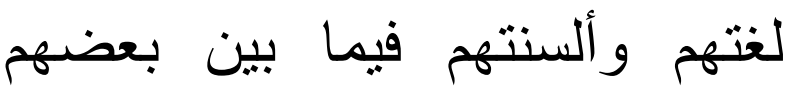
البعض بل و على مر العصور وكر لئه الدهور.

4. تحويل اللغة العربية إلى لغة تعليمية ذات قو اعد منضبطة 
ذكرت فيما سبق أن لغة أية أمّة هي صورة صسادقة لذوقها العام

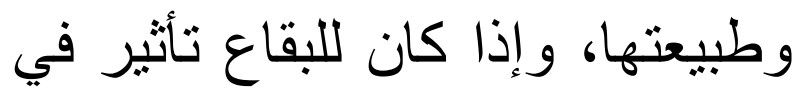
الطباع، فمما لا ريب فيه أن اللغة تتأثز كذلك حسب الناطقين بها، والعرب أمّة أكثرها ضـارب في في أنابن

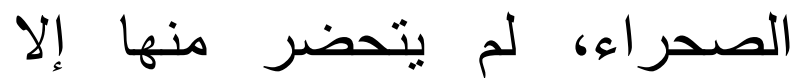

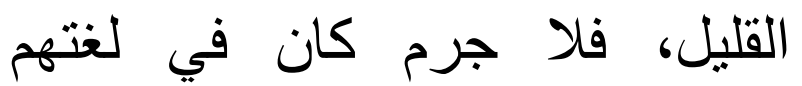
الخشن الجاف، و الحوشي الغريب،

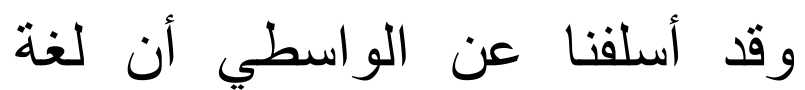
قريش كانت سهلة لمكان ياة التحضر التي كانت تحياها في ذللك. ولعل من يقرأ الأدب الجاهلي ويتدبره، يزداد إيماناً بما للحضارة من أثز ألفاظ اللغة، فإنه سيرى في أدب أهل الوبر كثيراً من مثل فيري فئل

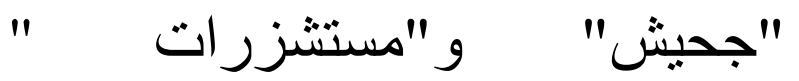
"وجحلنجع"، وما إلى ذلك مما ينفر

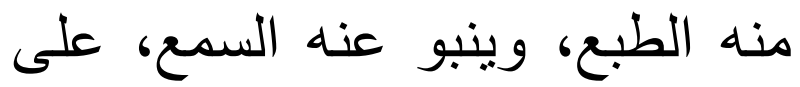
حين أنه يكاد لا يصادفه من ذلانه

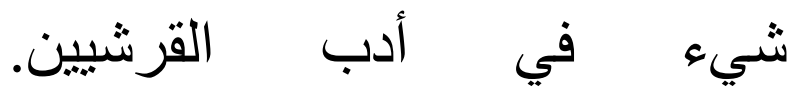
و القرآن الكريم ـفضلاً عن أنه نقل العرب من جفاء البداوة وخشونتها، إلى لين الحضارة
اختلاف اليهود و النصسارى...." فأمر عثمان( يجمع القرآن، وكان قصده

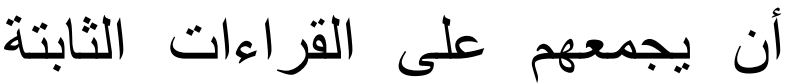

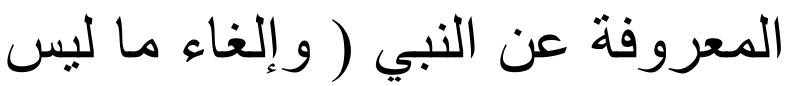
بقرآن خشية دخول الفساد و الثبهة

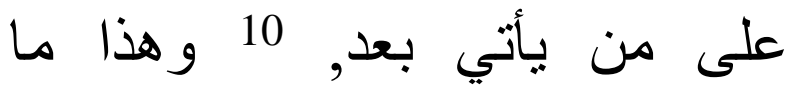
حصل، فقد ضعفت اللغة مع مرئ دورد

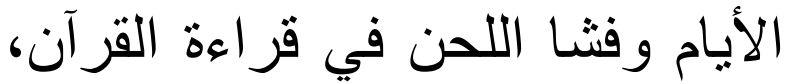
الأمر الذي أفزع أبا الأسود الدؤلي

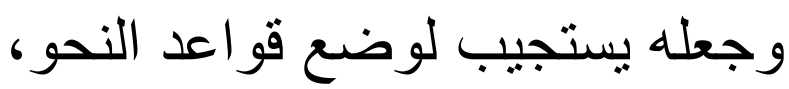
التي هي أساس ضبط هركات الحروف والكلمات، ومن ثم العمل على ضبط المصاحف بالثكل حفاظاً على قر اءة القر آن من اللحن و الخطأ.

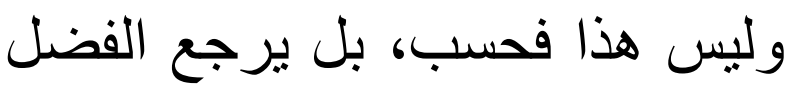

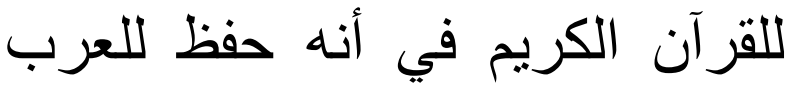

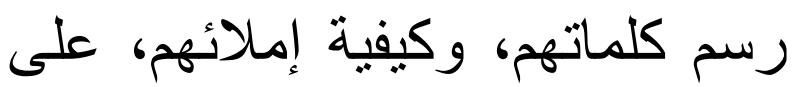
حين أن اللغات الأخرى قد اختلف ولفي إنهاء

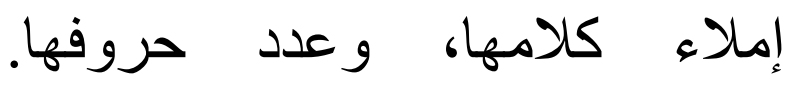

5. تهذيب ألفاظ اللغة العربية،

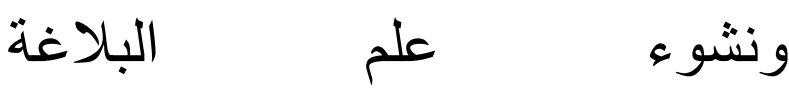
القرآن الكريم والدراسات الأدبية، ص 361. 10 
و الفارق كبير اً، ذلك أن القرآن الكريم

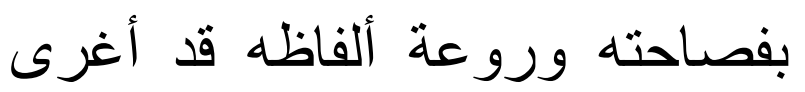
العرب على محاكاته، فأقبلوا إليه يزفون، ومن بحره ورياضه يستقون وينهلون، ومن ون وألفاظ و ومعانيه

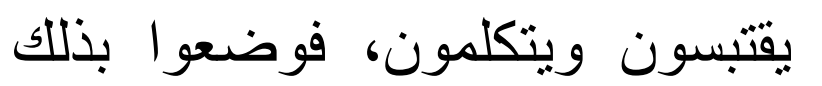
قواعد علوم البلاغة، بغاية الروعة فئون

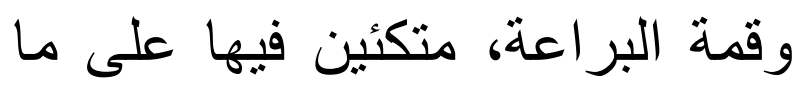

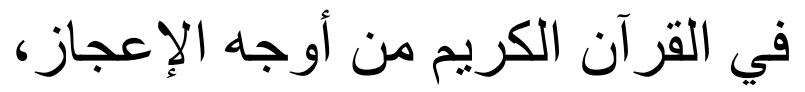

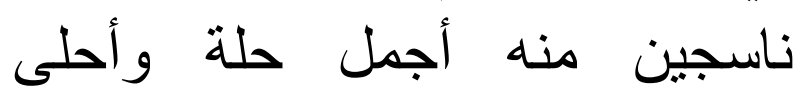
طراز، ولهذا نجد أبا الهلال ولهل

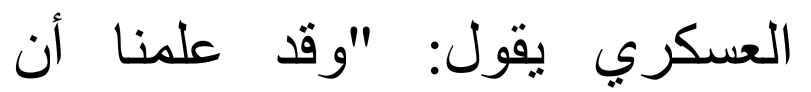
الإنسان إذا أغفل علم البلاغة و أخل

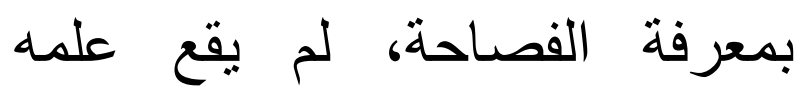

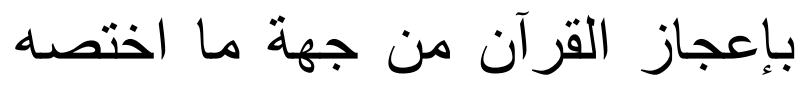
الله به من حسن التأليف، وبراعة ماعة التهان التركيب، وما شحنه به من الإيجاز البديع والاختصار اللطيف، وضمنه ونه لإنها

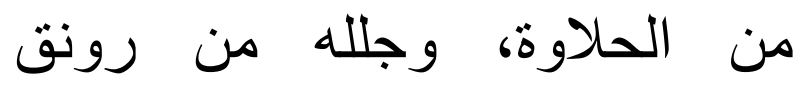
الطلاوة، مع سهولة كلمه وجز التها، و عذوبتها وساستها، إلى غير ذلك
ونعومتها، فنزلوا عن حوشيتهم، وتوخوا العذوبة في ألفاظهم، ـقدأ تخير لألفاظه أجمل ما تخف به به نطقاً في الألسن، وقرعاً للأسماع، حتى لأنى

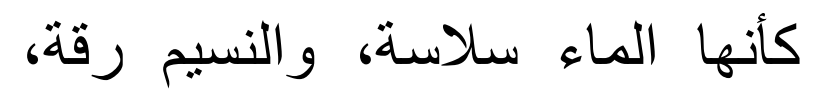
و العسل حلاوة، وهو بعد بالمكان الأسمى الذي أدهشهم وحير ألبابهم، وهو بالفيكان و أفهههم أن البلاغة شيء التهي وراء

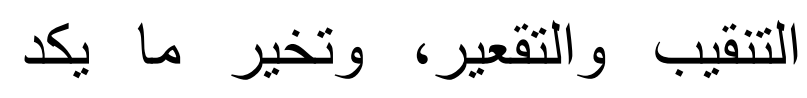
الألسن ويرهقها من الألفاظ، فعكفو التيز

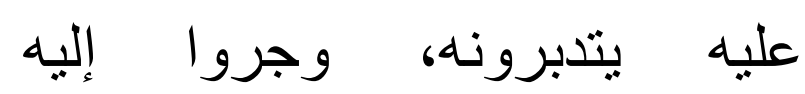
يستمعونه ذللك أن القرآن الكريم قد فئ

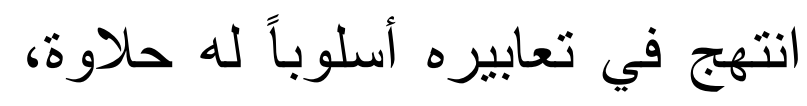

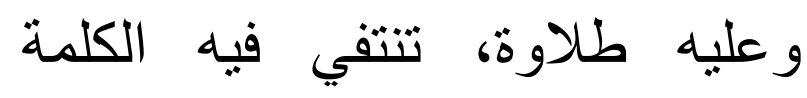
انتقاء، حتى كانت مفردات القرآن

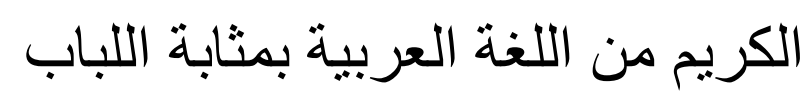

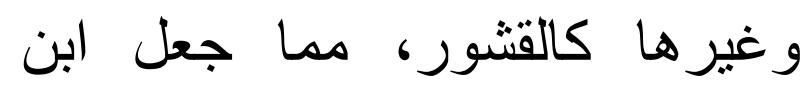

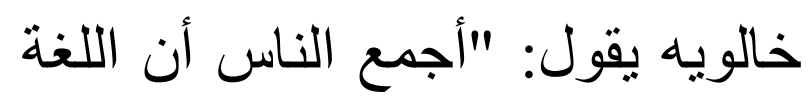

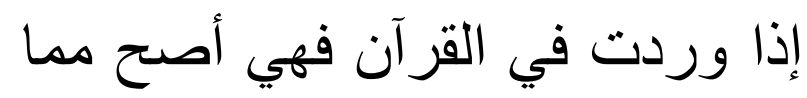

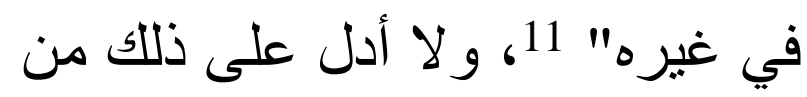

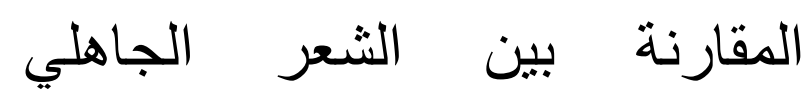

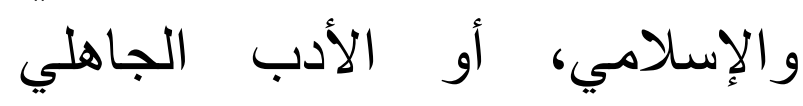

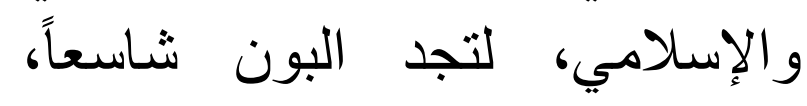

المز هر في علوم اللغة العربية، السيوطي، تحقيق محمد أبو المبر الفضل إبرآهيم، (ط. مصر) 1 /29 11 
داريخ ابو الفرج الاصفهاني,

الأغانى, بيروت: دار الفكر 1407هـ. الاساتذة بالأقطار اربر العربية,

المعجم فى الادب العربى وتاريخان,

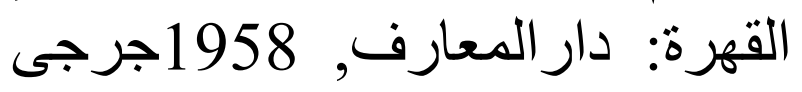
زيدان, ناريح ادب اللغدار اللغة العربية, بيروت: مكتبة البحوث و الدار اسات, 1997

احمد الهاشمى, جواهر البلاغة فى المعانى وابيان وابديع, الهئر مكتبة دار احياء الكتب العربية, 1960

احمد ابو سعد, معجم

و اعبار ات

التر اكيب الاصطلاحيةالعربية, بيروت: دار العلم للملايين, 1989

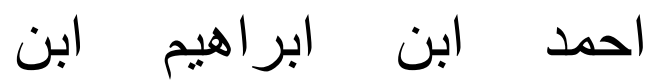

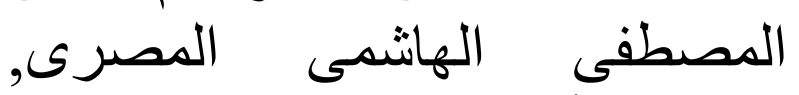
جو اهر الأدب في ادبيات و انشاء لغنة لغئة العربية. بيروت: دار الكتب العلمية.

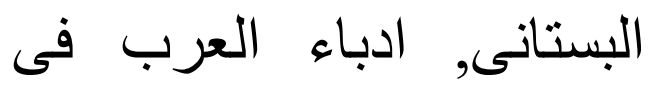
الجاهلية وصدر الاسلام, بيروت: دار الجبل, 1989 الثعالبى, فقه اللغة التغ وسر العربية, القاهرة, 1938
من محاسنه التي عجز عنها، وتحيرت عقو لهم فيها"12.

الخلاصة

اللغة العربية هي احدي اللغات

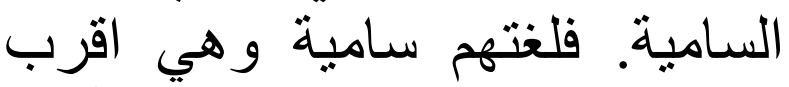

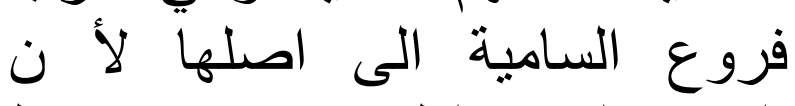

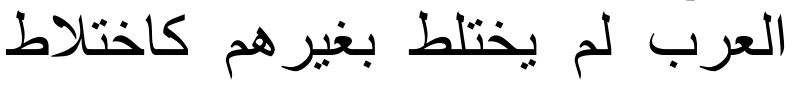
سو اهم ببعض الامم التى طغت لغت لغتها

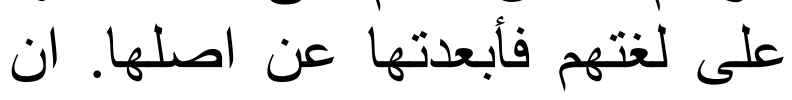
كجيء الاسلام ابرز الاحداث التئي كان لها اثرها في تطور فن الإنغ اللغة

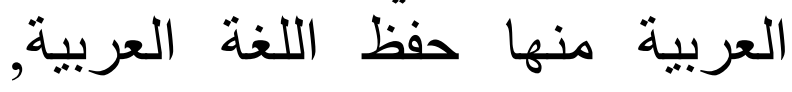
تقوية اللغة والرقي بها نحو الكمال,

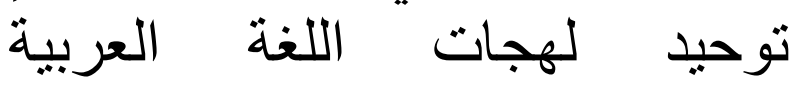
وتخليصها من اللهيخ الهجات القبلية الكثيرة, تحويل اللغة العربية إلى لغنة تعليمية ذات قو اعد منضبطة, تهذيب التهن

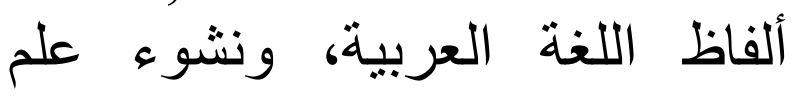
البلاغة.

\section{المراجع}

عبدالرحمنابن خلدون. الجزء إبز الاول. مقدمة العلامة ابن خلدون . كتاب الصناعتين أبو هلال العسكري، (ط. مصر) ص2.12 


$$
\begin{aligned}
& \text { الفاخوري, الموجز فى الأدب }
\end{aligned}
$$

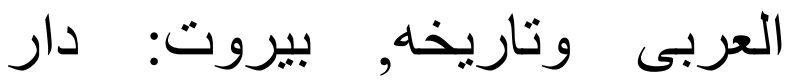

$$
\begin{aligned}
& \text { الجبل, الطبعة الثانية, } 1991 \\
& \text { كلية المعلمين الإسلامية, } \\
& \text { تاريخ الأدب العربي, الجزء الأولة الأول. } \\
& \text { الطبيعة الجديدة, دار السلام }
\end{aligned}
$$

محمدمحد داود, الدلالة

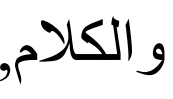

الثيخ أحمد الإسكندي والثيخ المصطفى عناني, الوسيط في الأدب الإبكان العربي و تاريخه, دار المعارف في الارف, 1978

شوقى ضيف, الفن و مذاهبه

فى النثر العربى, القاهرة: دار المعارف 